\title{
An analysis of member retention patterns for adult rare disease cohorts to support evaluating multiyear payment arrangements for novel therapies
}

\author{
E Anne Jackson, FSA, MAAA; Brenda Runyan, MBA; Luke Metz, ASA, MAAA; and James T Kenney, RPh, MBA
}

\section{What is already known about this subject}

- The market entrance of one-time administration cell and gene therapies for rare disease with clinical benefit extending over multiple years is causing payers to consider alternative payment arrangements, which depend on multiple factors, one of which is member retention.

- Retention studies are not typically performed by employers or health insurers on specific populations (eg, members with rare disease).

- Health plan members afflicted by rare medical conditions often have higher health care costs than their nonafflicted counterparts, and health plans are concerned about the risk of members using high-cost services and disenrolling from the plan.

\section{ABSTRACT}

BACKGROUND: Traditionally, treatment for chronic conditions addressed symptoms or was disease modifying and required lifelong periodic administration and recurring costs. Cell and gene therapies for rare diseases often require a short administration period relative to their expected long-term clinical benefit. Costs have historically been recognized when the service or treatment is administered, resulting in the potential for the cost associated with the possible long-term clinical benefit of cell and gene

\section{What this study adds}

- This study produced robust estimates for the length of time that adults diagnosed with a rare disease in the United States continue coverage with self-insured employers and fully insured health plans.

- Study results extend the visibility of commercial member retention to include adults with specific rare medical conditions, which can be useful to commercial health insurers when assessing alternative payment arrangements involving one-time administration cell or gene therapies with clinical benefits extending well beyond the year of administration.

- This study encourages health plans to assess retention rates for patients with rare disease, rather than overall member rates, when evaluating multiyear payment arrangements.

therapies being incurred during a short administration period. Innovative payment arrangements have been proposed to improve the synchronization of the payment and the emergence of the clinical benefit. Expected payments associated with a multiyear payment arrangement will depend on many factors, but key drivers of the payments include efficacy, durability of effect, mortality, and member retention. This research extends a previous study by analyzing member retention for adult patients with certain rare diseases.

\section{Author affiliations \\ E Anne Jackson, FSA, MAAA; Brenda Runyan, MBA; and Luke Metz, ASA, MAAA, Milliman, Inc., Indianapolis, IN. James T Kenney, RPh, MBA, JTKENNEY, LLC, Waltham, MA.}

\section{AUTHOR CORRESPONDENCE: \\ Brenda Runyan, 317.524.3545; \\ Brenda.Runyan@Milliman.com}


limited the study cohort to members who were either the subscriber or the subscriber's partner and were aged 18 years or older; dependent children were excluded from the analysis, regardless of age. The IBM MarketScan Commercial Claims and Encounters research database for the 10 years ending December 31, 2016, was used as the basis for the analysis. The analysis was completed using the lifetest procedure available in version 9.4 of the SAS Software System for Windows. The Kaplan-Meier method was used to produce retention rates. A log-rank test with chi-square statistic was used to determine statistically significant differences between pairs of curves.

RESULTS: The study found that the subscriber retention for the rare medical condition cohort is significantly higher than the allsubscribers cohort by at least 12 points at each 1 -year period. The finding was statistically significant $(P<0.0001)$ for the self-insured and fully insured cohorts. At year 5, approximately $20 \%$ more of the rare medical condition cohort was retained as compared with the allsubscribers cohort regardless of payer type. In addition, the study found that the probability of retention for adults with each rare medical condition in the rare disease cohort was also statistically significantly higher than all subscribers regardless of payer type.

CONCLUSIONS: In multiyear payment arrangements, it may be important to set expectations for member retention based on studies specific to particular member cohorts. Health insurers and plan administrators may have inaccurate expectations if standard assumptions based on all member populations are used. This study found that adults diagnosed with 1 of 7 rare medical conditions are retained longer, on average, than all adult subscribers.

Adults and children with certain rare diseases in the United States have begun to experience the life-changing value of cell and gene therapies. In the next few years, many more patients may have the potential to benefit from these advances in treatment paradigms. Traditionally, treatment for chronic conditions addressed symptoms or was disease modifying and required lifelong periodic administration and recurring costs. Cell and gene therapies for rare diseases often require a short administration period relative to their expected long-term clinical benefit. That is, multiple years of clinical benefit could be administered to a patient in a single dose or over a time period measured in weeks. Research is being conducted to explore potential innovative payment arrangements that would improve the synchronization of the payment for the therapy and the emergence of the clinical benefit., ${ }^{1,2}$ Consistent with this research, some therapy developers have expressed a willingness to enter into multiyear payment arrangements. ${ }^{3,4}$ Innovative agreements are difficult to manage when patients disengage from the plan or are lost to follow-up with providers.
In the United States, multiyear payment arrangements are novel. The expected payments associated with this approach will depend on many factors (and will vary based on the terms of the contract), but key drivers of the expected payments include efficacy, durability of effect, mortality, and member retention. ${ }^{2}$ Payers, including actuaries and other stakeholders, will need to inform these parameters with reasonable assumptions in order to develop appropriate estimates for the expected payments and any potential contracting strategies.

Within the employer-based group health insurance business, there are 2 factors that affect member retention (also known as turnover or churn): (1) the subscriber and/or their dependents leave the employer and (2) the employer switches insurers or plan administrators. Although insurers or plan administrators may conduct a membership retention study to help inform costs associated with membership attrition or retention, it is uncommon for insurers to conduct membership retention studies for cohorts defined at the member level, such as comparing cohorts defined by age or by the presence/absence of a chronic condition. Moreover, when membership retention studies are conducted, there is no external source available against which to benchmark the results. Insurers have no incentive to share the results of their studies publicly, and third parties do not have the plan-level data available to conduct independent analyses of plans. As a result, cohort-specific member retention studies are not readily available. Plans can easily validate the findings regarding retention, since these rates are calculated and reported annually.

In February 2019, we published an article in the Journal of Managed Care+Specialty Pharmacy that quantified the retention of commercial health insurance subscribers who had a pediatric dependent with 1 of 7 prospectively determined rare diseases. ${ }^{5}$ The 2019 study did not address retention of adults afflicted with rare medical conditions. In order to address the adult population, we conducted a literature search to discover other retention studies that could offer a basis for comparison, but none were found that addressed an adult cohort with a rare medical condition. We, therefore, designed a study that would allow us to analyze 7 prospectively determined rare medical conditions that affect adults. This study was performed using source data and methodology consistent with the previous study conducted for pediatric rare diseases. The analysis and results discussed in this current study extend the insights from the previous study into member retention patterns for adults with rare medical conditions. 


\section{FIGURE 1}

Exposure to Censored Observations (Self-Insured, Fully Insured)

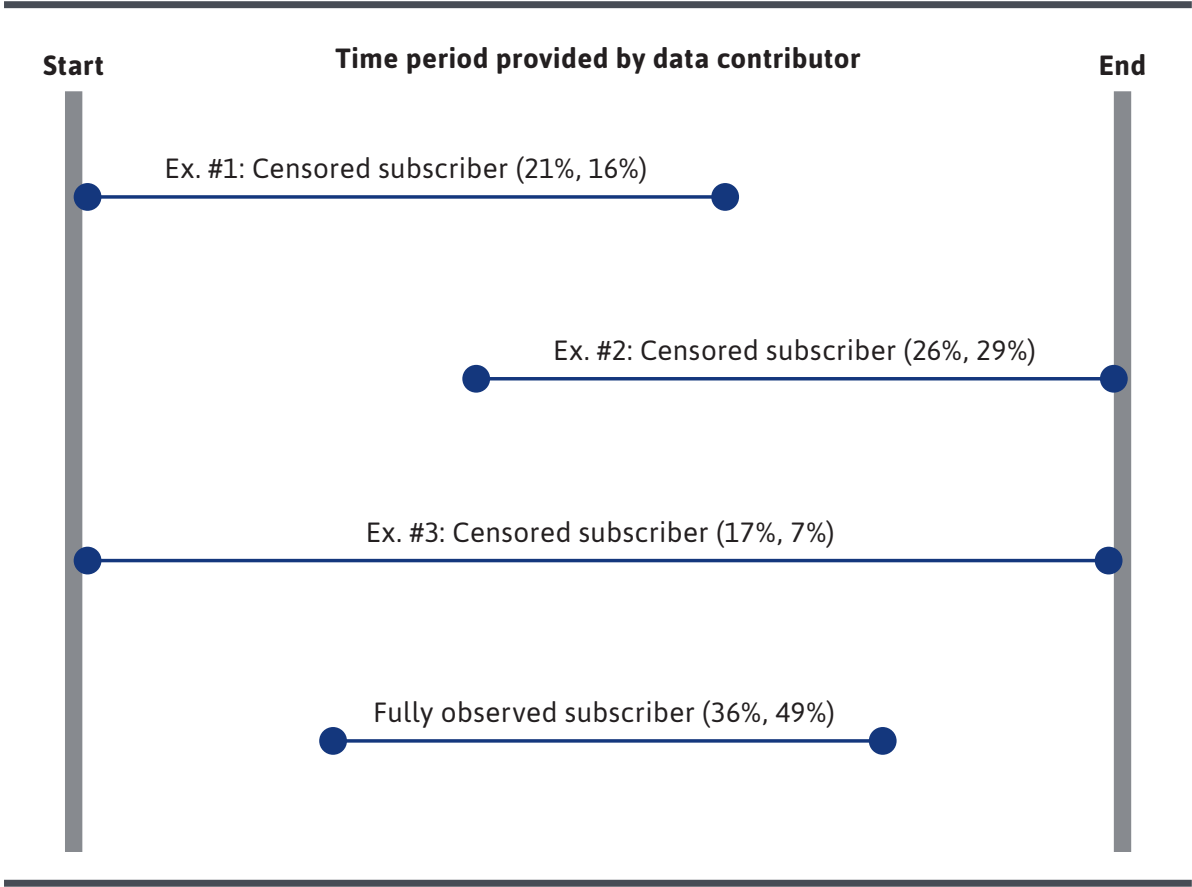

\section{Methods}

\section{DATA SOURCE}

IBM MarketScan Commercial Claims and Encounters (MarketScan) databases for the 10 years ending December 31, 2016, were used for this analysis, since direct access to plan administrator enrollment data was not publicly available.

MarketScan reflects claims collected from approximately 350 private-sector payers (data contributors) across the United States. These data reflect the health care experience of active employees and their dependents, early retirees, and individuals continuing their health coverage through the Consolidated Omnibus Budget Reconciliation Act (COBRA) option, all of whom are covered by the health benefit programs of large employers. No Medicaid or workers compensation data are included. Health plans use this type of study to examine their own data and apply any learnings or approach innovative contracting models with providers and manufacturers.

\section{STUDY POPULATION}

We identified 7 rare medical conditions for the analysis: cerebral palsy, cystic fibrosis, Gaucher disease, hemophilia, sickle cell disease, spina bifida, and thalassemia. Multiple rare medical conditions were used in order to produce a more credible study cohort than could have been realized by any single rare medical condition. The rare medical conditions were prospectively selected for this study based on the following shared characteristics: ability to identify the condition using International Classification of Diseases, Ninth/ Tenth Revision, Clinical Modification (ICD-9-CM and ICD-10-CM) diagnosis codes; rare medical condition based on the US prevalence rate (ie, fewer than 200,000 individuals); diagnosed at birth or early childhood; typical results in significant medical and/or pharmacy expenses; and expectation for patients to live into adulthood but may have a shortened lifespan.

The study cohort was limited to members who were either the subscriber or the subscriber's partner and were aged 18 years or older; dependent children were excluded from the analysis, regardless of age. Subscribers (or their partners) in the study cohort were flagged as having a rare medical condition if their claims experience included a nonlaboratory/ nonradiology diagnosis on 2 separate claim dates for at least 1 of the 7 rare medical conditions during the study period. For comparison, retention curves were generated for all subscribers, regardless of the diagnosis of a rare medical condition (ie, the rare medical condition cohort is a subset of the all-subscribers cohort).

The medical conditions were selected before any analysis on the data to avoid selection bias based on the included conditions. The data collection period included the time frame of the transition from use of ICD-9-CM codes to the use of ICD10-CM codes. Accordingly, the codes from both revisions were used. To ensure that all equivalent ICD-10-CM codes were captured, the 2018 ICD10-CM General Equivalence Mappings published by the Centers for Medicare \& Medicaid Services was used. The diagnosis codes used to identify the rare diseases included in the study can be found in Supplementary Table 1 (available in online article).

We stratified the cohorts by funding type in order to create 4 study cohorts: (1) self-insured-all subscribers, (2) self-insured-rare medical condition, (3) fully insured-all subscribers, and (4) fully insured-rare medical 


\section{TABLE 1 Subscriber Demographics}

\begin{tabular}{|c|c|c|c|c|c|c|c|}
\hline \multicolumn{4}{|c|}{ Self-insured } & \multicolumn{4}{|c|}{ Fully insured } \\
\hline $\begin{array}{c}\text { Subscriber } \\
\text { characteristics }\end{array}$ & All subscribers & $\begin{array}{l}\text { Subscriber or } \\
\text { partner with a } \\
\text { rare medical } \\
\text { condition }\end{array}$ & $P$ value & $\begin{array}{c}\text { Subscriber } \\
\text { characteristics }\end{array}$ & All subscribers & $\begin{array}{l}\text { Subscriber or } \\
\text { partner with a } \\
\text { rare medical } \\
\text { condition }\end{array}$ & $P$ value \\
\hline Observations, n (\%) & $19,621,014$ & $27,418(0.1 \%)$ & & Observations, n, (\%) & $39,274,850$ & $41,413(0.1 \%)$ & \\
\hline Observation months & $725,056,027$ & $1,615,406$ & & Observation months & $860,267,578$ & $1,503,708$ & \\
\hline $\begin{array}{l}\text { Average age of } \\
\text { subscriber }\end{array}$ & 42.8 years & 45.5 years & $<0.0001$ & $\begin{array}{l}\text { Average age of } \\
\text { subscriber }\end{array}$ & 41.7 years & 45.0 years & $<0.0001$ \\
\hline Male (\%) & $53.5 \%$ & $55.7 \%$ & $<0.0001$ & Male (\%) & $53.9 \%$ & $53.8 \%$ & 0.6832 \\
\hline $\begin{array}{l}\text { Include spouse on } \\
\text { coverage (\%) }\end{array}$ & $42.7 \%$ & $61.9 \%$ & $<0.0001$ & $\begin{array}{l}\text { Include spouse on } \\
\text { coverage }(\%)\end{array}$ & $33.9 \%$ & $51.3 \%$ & $<0.0001$ \\
\hline
\end{tabular}

condition. Cohorts 2 and 4 comprised subscribers who either themselves and/or their covered partners were identified as having one of the rare medical conditions.

\section{STUDY APPROACH AND STATISTICAL ANALYSIS}

Employers and health plans can conduct relatively straightforward retention studies because they have the benefit of a comprehensive set of data that includes complete enrollment information for all subscribers. This study used incomplete enrollment history, since contributors to the MarketScan database can change on an annual basis.

In order for enrollment data for a member to be included in the database, the member must be enrolled during the time frame in which the associated data contributor is part of the database. That is, the first and last enrollment date for each member are not always available. It is common in any member retention study for observations to be right censored because many members will still be enrolled at the time the membership retention study is conducted (ie, we have not observed their final enrollment date yet).

The MarketScan databases have another source of censoring due to members for whom the first enrollment date has not been observed (or we are not certain we have observed their first enrollment dates). This occurs when a member's earliest observed enrollment date is associated with the first submission from the data contributor. Figure 1 is a schematic that displays the potential sources of censoring and the percentage of subscribers associated with each source of censoring.

The analysis was completed using the lifetest procedure available in Version 9.4 of the SAS Software System for Windows (SAS Institute). The lifetest procedure uses the Kaplan-Meier survival estimator which accounts for censored data. A log-rank test with chi-square statistic was used to determine statistically significant differences between pairs of curves. For each of the 4 study cohorts, the Kaplan-Meier method produced estimates of the probability of the subscriber remaining enrolled at months 1 through 120 following the first enrollment date.

\section{Results}

Table 1 provides a count of subscribers associated with the cohorts and select demographic information. The rare medical condition cohorts were slightly older, on average, and were more likely to include an adult dependent than their all-subscriber counterparts.

The probability of subscriber retention over time is presented in Figure 2 for all 4 cohorts: (1) self-insured - all subscribers, (2) self-insured - rare medical condition, (3) fully insured - all subscribers, and (4) fully insured - rare medical condition. Because we used a 10-year study period, the maximum possible enrollment period was 120 months.

Figure 2 provides the results for all 4 subscriber cohorts. Among all subscribers (gray curves) and those with a rare medical condition (blue curves), the subscriber retention for the self-insured cohort was significantly higher than that of the fully insured cohort at all time periods $(P<0.0001)$.

The second comparison observed was between the allsubscribers cohort and the rare medical condition cohort (gray vs blue curve). For each employer type, the rare medical condition cohort was retained longer relative to all subscribers. At year 5 (month 60 ), approximately $20.8 \%$ more of the rare medical condition cohort remained with the plan compared with the all-subscribers cohort, both self-insured and fully insured members. Further detail on these comparisons is provided in Table 2. 


\section{FIGURE 2 Probability of Subscriber Retention}

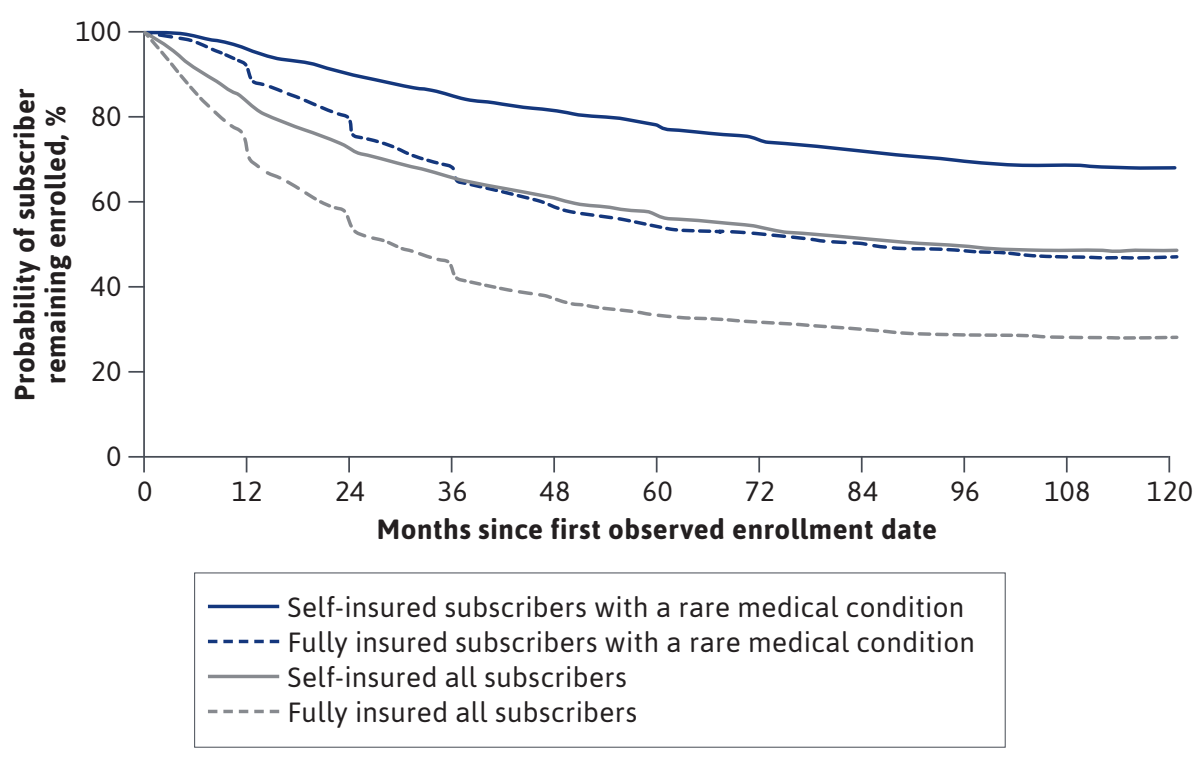

An additional analysis comparing the retention rate for the subcohorts with each rare medical condition with that of the rare medical condition cohort for the fully insured and self-insured populations showed that retention rates for self-insured adults with cerebral palsy, hemophilia, and spina bifida were not statistically significantly different from that observed for the rare medical condition cohort. However, the probabilities of retention for adults with Gaucher disease and thalassemia were observed to be higher than that for the rare medical condition cohort $(P=0.0002$, $\mathrm{P}<0.0001$, respectively) and still statistically significantly higher than all subscribers. The probability of retention for adults with cystic fibrosis and sickle cell disease were each observed to be lower than the rare medical condition cohort $(P=0.0015, P<0.0001$, respectively) but still statistically significantly higher than all subscribers $(P<0.0001$ for all rare medical conditions).
Within the fully insured population, the results by rare medical condition followed a similar pattern as with the self-insured population. Retention rates for adults with cerebral palsy, hemophilia, and spina bifida were not statistically significantly different from that observed for the rare medical condition cohort. The probability of retention for adults with Gaucher disease and thalassemia were observed to be higher than that observed for the rare medical condition cohort $(P=0.0112, P<0.0001$, respectively) and still statistically significantly higher than all subscribers. The probability of retention for adults with cystic fibrosis and sickle cell disease were each medical condition cohort $(\mathrm{P}=0.0047$, $\mathrm{P}<0.0001$, respectively) but still statistically significantly higher than all subscribers $(P<0.0001$ for all rare medical conditions). observed to be lower than the rare

\section{Discussion}

Although there are approximately 7,000 identified rare diseases, only a few hundred have approved treatments. ${ }^{6}$ Additionally, many existing chronic disease management approaches, including pharmaceutical interventions, focus on addressing symptoms but do not address the underlying cause of the disease. With the handful of cell and gene therapies that have been approved by the FDA in the past few years, this is beginning to change.

In fact, there are currently 155 US-based companies actively developing cell and gene therapies for rare disease. ${ }^{7}$ Self-insured employers and fully insured health plans will need to contemplate their policies for coverage of such therapies now or in the near future. With dozens of gene therapies currently in phase 3 clinical trials in the United States for patients aged under 65 years, it becomes increasingly more likely that many employers and health plans will experience a request for such treatments. ${ }^{8}$ One of the considerations self-insured employers and fully insured health plans may explore when contemplating the inclusion of gene therapies in their medical policies is whether the expected duration of benefit extends beyond the expected retention of the beneficiary or the projected cost of any alternative treatment options.

Expected retention for member populations where cell and gene therapies are likely to become available in the next 3-5 years could be an important factor in the financial evaluation of multiyear contracting arrangements offered by manufacturers. While member retention or employee turnover is known for some employers and health plans, few, if any, have investigated populations at the level to know whether certain populations (eg, adults or children 


\section{TABLE 2 Probability of Subscriber Retention at Plan Year Anniversaries}

\begin{tabular}{|c|c|c|c|c|c|c|}
\hline \multirow[b]{2}{*}{ Month } & \multirow[b]{2}{*}{ All subscribers } & \multicolumn{2}{|c|}{ Self-insured } & \multirow[b]{2}{*}{ All subscribers } & \multicolumn{2}{|c|}{ Fully insured } \\
\hline & & $\begin{array}{l}\text { Subscriber or } \\
\text { partner with rare } \\
\text { medical condition }\end{array}$ & Hazard ratioa & & $\begin{array}{l}\text { Subscriber or } \\
\text { partner with rare } \\
\text { medical condition }\end{array}$ & Hazard ratio ${ }^{a}$ \\
\hline 12 & $82.3 \%$ & $95.4 \%$ & $26.0 \%$ & $69.8 \%$ & $88.8 \%$ & $37.1 \%$ \\
\hline 24 & $72.0 \%$ & $89.6 \%$ & $37.1 \%$ & $53.3 \%$ & $75.9 \%$ & $51.6 \%$ \\
\hline 36 & $65.3 \%$ & $84.8 \%$ & $43.8 \%$ & $42.2 \%$ & $64.9 \%$ & $60.7 \%$ \\
\hline 48 & $60.5 \%$ & $81.0 \%$ & $48.1 \%$ & $36.6 \%$ & $58.4 \%$ & $65.6 \%$ \\
\hline 60 & $56.6 \%$ & $77.4 \%$ & $52.1 \%$ & $33.3 \%$ & $54.1 \%$ & $68.8 \%$ \\
\hline 72 & $53.5 \%$ & $74.3 \%$ & $55.3 \%$ & $31.8 \%$ & $52.2 \%$ & $70.1 \%$ \\
\hline
\end{tabular}

aThe hazard ratio is defined as (1 - all subscribers probability of retention) / (1 - rare cohort probability of retention).

with certain rare diseases) closely align with that of their total membership or employee base. Additionally, the prevalence and incidence of these rare diseases is so small that in most cases many employers and health plans may have no or very few members with a given rare disease, making the analysis at this level unreliable.

The analyses presented in this study used claims from a database that contains observations of sufficient size to allow for statistically significant conclusions about the rare disease populations. As shown in Table 1, the self-insured cohort included 19,621,014 subscribers, with $0.14 \%$ of those making up the subscribers or partner in the rare medical condition cohort, and although larger in size at 39,274,850, the fully insured cohort's rare medical condition cohort was similar in percentage at $0.11 \%$.

We anticipated that subscriber retention in self-insured plans would be longer than that of fully insured plans based on the results of our previous pediatric study, ${ }^{5}$ as well as an understanding of differences that underlie plan dynamics between these 2 cohorts. Employers using fully insured health plans may reconsider their health plan provider more often in order to ensure that they are enrolled with a competitive premium. Self-insured employers may have less financial incentive to move between third-party administrators. Therefore, within self-insured payers, we expect most observed turnover to be attributable to the employee changing employers. The higher turnover observed within the fully insured cohort may reflect the incremental turnover associated with the employer moving to a health plan that is not a contributor to the data source used in this research.

The research for this study suggests that member retention assumptions should be informed by studies tailored to the population indicated for treatment. Similar to the observations in the pediatric study ${ }_{,}^{5}$ our research for adult subscribers illustrates a higher retention rate $(\mathrm{P}<0.0001)$ for subscribers with a rare medical condition compared with all subscribers in the self-insured and fully insured employer groups, as seen in Figure 2.

As more cell and gene therapies are approved by the FDA for rare medical conditions, the subscriber behavior observed in this study may change. This study may serve as a benchmark from which to evaluate observations of retention behavior for commercially covered subscribers associated with rare diseases over the next 3-5 years.

\section{LIMITATIONS}

Certain limitations should be considered when reviewing the results of this study. First, the period of time studied overlapped with a market-shaping event in the commercial health care market. The Affordable Care Act (ACA) changed several factors that may have influenced the results. During this period, the lifetime maximum limit was removed and the dependent age cutoff was increased from age 18 years to age 26 years before a dependent would no longer be eligible to be covered on a parent's plan. Insurance coverage for preexisting conditions also became a requirement. The sample size before and after the implementation of the ACA was unable to be assessed because of the phase-in portion for some of the changes resulting from the ACA.

Second, this study was not designed to assess the rationale that families may use when making health insurance coverage decisions. Additional investigation via surveys and interviews could address the underlying factors involved.

Because of the size of the sample, the experience with the MarketScan databases was expected to be representative of employer-based group health insurance business, although it may not have represented the experience 
of any individual employer or plan administrator.

In addition to changes in the commercial health care market, changes in the prognosis for a medical condition could have affected subscriber retention patterns. The time period of this analysis may have captured innovations in treatment that could have affected retention patterns for any of the study cohorts. Additionally, the treatment with cell and gene therapies, in the future, could result in a change in subscriber retention patterns.

\section{Conclusions}

For self-insured employers and fully insured health plans evaluating multiyear payment arrangements, it may be important to set expectations for patient retention based on studies specific to particular member cohorts. Health insurers and plan administrators may have inaccurate expectations if they use a standard assumption for all patient populations. Consistent with our previous research on pediatric members, this study found that, in general, adults diagnosed with 1 of 7 rare medical conditions are more likely to be retained longer than all adult subscribers for self-insured employers and for fully insured health plans.

\section{DISCLOSURES}

Milliman received funding from bluebird bio for the conduct of this study and fees from AveXis, outside the submitted work. Jackson, Runyan, and Metz are employed by Milliman. Jackson and Metz are members of the American Academy of Actuaries and meet the qualification standards for performing the analyses in this report. Kenney is an independent managed care consultant and received consulting fees from Milliman during the conduct of this study; Kenney also serves as preceptor for the Massachusetts College of Pharmacy and Health Sciences, is immediate past president of the Academy of Managed Care Pharmacy, and is a member of the Massachusetts Pharmacists Association Legislative Committee.

\section{ACKNOWLEDGMENTS}

The authors thank Dave Liner for his review of the manuscript.

\section{REFERENCES}

1. NEWDIGS FoCUS. Precision financing solutions for durable/potentially curative therapies. White paper. Massachusetts Institute of Technology, Center for Biomedical Innovation. January 24, 2019. Accessed December 11, 2020. https:// newdigs.mit.edu/sites/default/files/ MIT\%20FoCUS\%20Precision\%20 Financing\%202019F201v023.pdf

2. Serre D, Buckle J, Jackson A, Naber J. Evaluating payment models for highcost curative therapies report. Society of Actuaries. October 2018. Accessed December 11, 2020. https://www.soa. org/globalassets/assets/files/resources/ research-report/2018/evaluating-payment-models.pdf
3. Novartis. AveXis announces innovative Zolgensma ${ }^{\circledR}$ gene therapy access programs for US payers and families. Press release. May 24, 2019. Accessed December 11, 2020. https://www.novartis.com/ news/media-releases/avexis-announcesinnovative-zolgensma-gene-therapyaccess-programs-us-payers-and-families

4. bluebird bio, Inc. Recode the status quo: a bold and balanced path to a sustainable payment model for gene therapies. Fact sheet. Accessed December 11, 2020. http://investor.bluebirdbio.com/static-files/ e4332043-0470-4633-ac65-7478f8d8acd5

5. Kuester MK, Jackson EA, Runyan BM, Pezalla EJ, Nussbaum SR. The effect of a pediatric rare disease on subscriber retention rates for commercial health insurers in the United States. J Manag Care Spec Pharm. 2019;25(2):186-95. doi:10.18553/jmcp.2018.18205

6. National Center for Advancing Translational Sciences. Gene therapy platform for rare diseases. Updated March 17, 2020. Accessed December 11, 2020. https://ncats.nih.gov/trnd/projects/ gene-therapy

7. Alliance for Regenerative Medicine. Regenerative medicine and rare disease. February 2019. Accessed December 11, 2020. http://alliancerm.org/wp-content/ uploads/2019/02/Rare-Disease-Report2019-FINAL.pdf

8. National Library of Medicine. ClinicalTrials.gov database. Accessed December 11, 2020. https://clinicaltrials. gov/ 